\title{
Evaluation of Agricultural Ecosystem Service Value in Arid and Semiarid Regions of Northwest China Based on the Equivalent Factor Method
}

\author{
Yi Jia ${ }^{1}$ Yang $\mathrm{Liu}^{2,3} \cdot$ Songlin Zhang ${ }^{1}$
}

Received: 27 November 2020 / Accepted: 15 March 2021 / Published online: 6 April 2021

(c) The Author(s), under exclusive licence to Springer Nature Switzerland AG 2021

\begin{abstract}
A reasonable assessment of the value of ecosystem services is an effective measure to maintain the normal operation of the ecosystem and adjust the balance between economic development and the ecological environment. With the help of the related concepts of ecosystem services, this paper establishes an evaluation framework system and adopts the widely used and comprehensive evaluation method of equivalent factors, which is a rapid accounting tool used for the evaluation of ecosystem services. The value of agricultural ecosystem services was estimated from 2008 to 2017 in a typical arid-semiarid region, and nine ecosystem service functions were analyzed. Our research showed that from 2008 to 2017 the value of agricultural ecological services in Gansu Province increased annually, and the annual growth rate in 2012 was the highest (15\%). The results showed that the selection of appropriate methods could quickly and effectively evaluate the value of agricultural ecosystem services. In-depth research on the function and value of agroecological services could better promote the sustainable development of agroecosystems and maintain the balance and integrity of ecological service functions. Evaluation of the balance and integrity of agricultural ecosystem ecological service functions in arid semi-arid regions will provide recommendations for land use and sustainable development and ecological environment protection in these regions.
\end{abstract}

\section{Highlights}

-Agricultural ecosystem services have changed in an arid and semiarid region of China in recent decades.

- We reflect the results of China's ecological progress.

- This study provides advice on agricultural development of other developing countries.

Keywords Agroecological service value $\cdot$ Equivalent factor method $\cdot$ Contribution rate of value $\cdot$ Interannual changes $\cdot$ Gansu Province

Songlin Zhang

zhangsonglin65@nwnu.edu.cn

Extended author information available on the last page of the article 


\section{Introduction}

Arid and semiarid regions account for approximately $40 \%$ of the world's land area. However, the improper use of natural resources has caused a series of environmental problems, such as falling water levels, land desertification and salinization, reduced vegetation and increased pollution (Zhu et al. 2016). The loss of the natural environment and agricultural land are particularly severe ( $\mathrm{Lu}$ et al. 2015; Zhou et al. 2015), and thus, the sustainable development of the local society and economy has been greatly affected (Peng et al. 2019). Other developing countries experiencing urbanization and industrialization may face similar problems (Abd-Elaty et al. 2020; Azaiez et al. 2020; Haghighi et al. 2020; Sharafatmandrad and Mashizi 2021). With the strength of environmental protection and the consideration of human themselves, increasing attention needs to be paid to the fragility, sensitivity and security issues of the ecological environment in arid and semiarid regions.

Natural ecosystem services are the material basis for human survival and development, critical for the sustainable development of humans (Zhao et al. 2006; Wu 2013), and beneficial for policy and decision making (Cortinovis and Geneletti 2018; Posner et al. 2016). Constanza et al. (1997) subdivided the types of ecological services, proposed quantitative evaluation methods, and promoted quantitative research on ecological services. A reasonable assessment of the value of ecosystem services is an effective measure to maintain the normal operation of the ecosystem, ensure ecological safety, and adjust the balance between economic development and the ecological environment.

Agriculture represents humankind's largest engineered ecosystem, as agricultural land use accounts for one-third of the global terrestrial surface (approx. 4.9 billion ha) (FAO 2018). Livestock husbandry on grasslands ( 3.3 billion ha) accounts for a much larger area than crop production (1.6 billion ha) (Scheffers et al. 2016). Agricultural ecosystems provide and rely upon important ecosystem services (Zhang et al. 2007; Duguma et al. 2019). Research on agroecosystem services began in the 1990s. Researchers have shown that the evaluation and prediction of agroecological services contribute to agroecosystem protection (Longato et al. 2019; Khosravi Mashizi et al. 2019; Del Rio et al. 2020). Some researchers have focused on the regional impacts of ecosystem services (Chen et al. 2020; Yang et al. 2020; Zhong et al. 2020), especially the ecosystem service values (ESVs) of grasslands and forests (Cao et al. 2020). Sun et al. (2021) evaluated the agroecological services in North China and predicted their changes under different land-use scenarios. In addition, A good ecological environment will help control a large number of infectious disease epidemics, e.g., the current domestic and foreign rampant novel coronavirus epidemic situation caused by 2019-nCoV. Although the science of this hypothesis remains to be further studied, it shows that the role of the rural ecological environment and its ecosystem services in preventing and controlling epidemics deserves much more attention (Dietz et al. 2020; Wang and Su 2020).

Since the release of the Millennium Ecosystem Assessment (Millenium Ecosystem Assessment 2005), there have been three main methods used to evaluate the value of ecosystem services: the energy method, the InVEST model, and the economic methods. The energy method provides an ESV measurement approach by evaluating the biophysical flows used to support its generation (Odum 1996). The InVEST model maps and evaluates multiple ecological services (Kadaverugu et al. 2021). Economic methods can evaluate the economic value of an ecological system or its services to describe the interdependency of human economies and natural ecosystems (Farber et al. 2002; Zhang et al. 2010), thereby ensuring the sustainable use of those ecosystem services. There is no unified 
ESV evaluation system in China, although Xie et al. (2003) improved the ESV estimation method proposed by Costanza et al. (1997).

Because the understanding of the equilibrium relationship between the natural productivity of agricultural ecosystems and economic productivity is not deep enough, the integrity of the structure and function of agroecosystems is damaged in the process of pursuing agricultural economic benefits (Swinton et al. 2007). The uneven distribution and utilization of agricultural resources may lead to poor energy flow in the agroecosystem, hindered material circulation and delayed information transmission, eventually paralyzing the agroecosystem and worsening its original sociality, high productivity and volatility. Therefore, an in-depth study of the function and value of agroecological services can provide a scientific basis for the sustainable development of agroecosystems and the maintenance of the equilibrium and integrity of ecological service functions. The long-term preservation of agricultural landscapes that provide multiple ecosystem services must be a priority. Therefore, management actions on these landscapes should consider a spatial assessment of ecosystem services, and an ecosystem services valuation could inform and support the planning process to achieve sustainability (Santos-Martín et al. 2019).

Due to the special research theme of agroecosystem services, there are few studies on agroecosystem services in arid and semiarid regions. Thus, this paper studied the agroecosystem services in Gansu Province as an example to explore the changes in agroecosystem service value in the arid and semiarid areas of Northwest China during the past two decades; the results are expected to provide a scientific basis for the accurate and efficient allocation of land resources, scientific management of ecosystems, rational regional planning and sustainable land development in China and other countries with similar situations.

\section{Materials and Methods}

\subsection{Study Area}

Gansu Province, which includes 12 prefecture-level cities and two autonomous prefectures, is located in the arid inland area of Northwest China and the upper reaches of the Yangtze and Yellow Rivers, $32^{\circ} 31^{\prime} \sim 42^{\circ} 57^{\prime} \mathrm{N}, 92^{\circ} 13^{\prime} \sim 108^{\circ} 46^{\prime} \mathrm{E}$; the annual average temperature is $2 \sim 10^{\circ} \mathrm{C}$, and the annual average precipitation is $250 \sim 420 \mathrm{~mm}$. The lowest elevation is $586 \mathrm{~m}$, the highest elevation is $5696 \mathrm{~m}$, and the average elevation is $5156 \mathrm{~m}$; the study area covers an area of approximately 425,900 square kilometers (as of the end of 2017). Three plateaus, i.e., the Loess Plateau, the Qinghai-Tibet Plateau and the Inner Mongolia Plateau, meet here, and the terrain is undulating, crisscrossed with mountains, high elevation differences, mountains, basins, plains, deserts and Gobi, and other landform types that are rich and diverse (Fig. 1).

In addition to the Yellow River, three inland rivers, the Heihe River, the Shiyang River and the Shule River, are located in the Hexi Corridor of Gansu Province, and they provide water to oasis agroecosystems. For example, the Heihe River is the second largest inland river in Northwest China, but its ecological environment is sensitive and fragile ( $\mathrm{Li}$ and Pan 2018). The Ejina Oasis in the lower reaches of the Heihe River provides ecological protection for the other areas in northern China. Serious desertification and fragile ecological environments are popular issues in this area. Therefore, it is an important ecological barrier of the Qinghai-Tibet Plateau and the "Northern Sand Belt" and has a very important position in Northwest China and even in the whole country. 


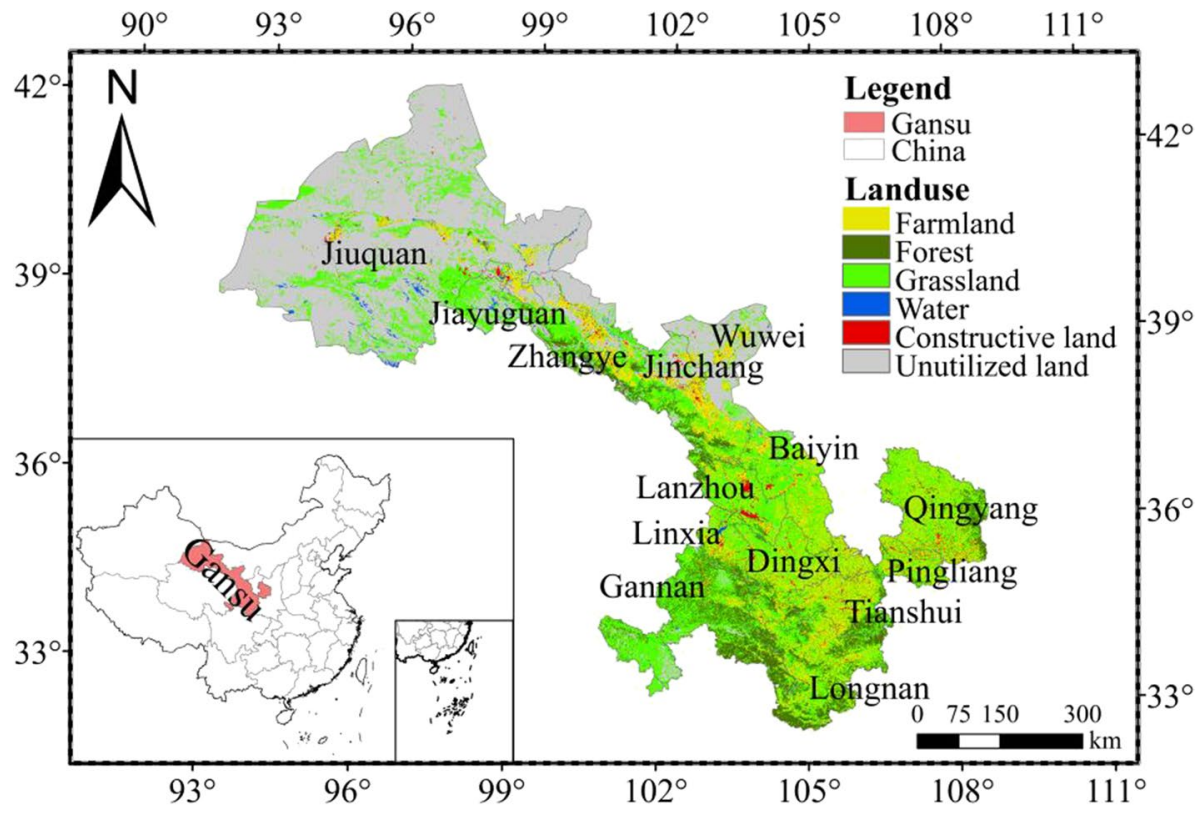

Fig. 1 Location of the study area

\subsection{Data Sources}

The data for different agricultural land-use types in Gansu Province from 2008 to 2017 used in this study were from the China Statistical Yearbook. The six land-use types corresponded to the six ecosystem types, i.e., forest, grassland, water body, wetland, farmland and desert, in the "Chinese Land ESV per Unit Area" table by Xie et al. (2003).

The sown area of the three main crops (wheat, corn and potato) in Gansu Province (2008-2017) came from the Gansu Provincial Statistical Yearbook and China Statistical Yearbook. The average prices of wheat, corn and potatoes were calculated based on the China Price Yearbook and the consumer price index.

\subsection{Ecosystem Service Value Evaluation}

Choosing an appropriate method to evaluate the service value of agricultural ecosystems is an effective measure to ensure the normal functioning of ecosystem services and is an important way to achieve regional ecological security and promote sustainable social development. This is even more important for arid and semiarid regions. Therefore, this study adopted the method developed by Xie et al. (2003) to estimate the ESV unit area of China's terrestrial ecosystem to estimate the value of agricultural ecosystem services in Gansu Province from 2008 to 2017.

The ESV per unit area of different terrestrial ecosystems shown in Table 1 was used to estimate the ESV in Gansu Province from 2008-2017. Based on the data for the three main crop areas (unit: ha) and the total output value (unit: US Dollars; All the values 
Table 1 Ecosystem service value per unit area for each Chinese ecosystem

\begin{tabular}{llllccc}
\hline Items & Forestland & Grassland & Farmland & Wetland & Water body & Desert \\
\hline GR & 3.50 & 0.80 & 0.50 & 1.80 & 0.00 & 0.00 \\
CR & 2.70 & 0.90 & 0.89 & 17.10 & 0.46 & 0.00 \\
WC & 3.20 & 0.80 & 0.60 & 15.50 & 20.38 & 0.03 \\
SFC & 3.90 & 1.95 & 1.46 & 1.71 & 0.01 & 0.02 \\
WT & 1.31 & 1.31 & 1.64 & 18.18 & 18.18 & 0.01 \\
BM & 3.26 & 1.09 & 0.71 & 2.50 & 2.49 & 0.34 \\
FP & 0.10 & 0.30 & 1.00 & 0.30 & 0.10 & 0.01 \\
RMP & 2.60 & 0.05 & 0.10 & 0.07 & 0.01 & 0.00 \\
EC & 1.28 & 0.04 & 0.01 & 5.55 & 4.34 & 0.01 \\
\hline
\end{tabular}

of this article are converted by the Renminbi for the US dollars, the exchange rate is $\$ 0.15$ ) of food crops, the output (raw materials production; RMP) value of the three main crops per unit area (unit: Dollars /ha) was obtained for each year (Xie et al. 2003). According to Xie et al. (2003), the equivalent factor of ESV in China was defined as $1 / 7$ of the economic value of food yield per unit area of farmland (i.e., the economic value of natural grain per unit farmland). In addition, according to the 'China Terrestrial Ecosystem Unit Area Value Equivalent Scale of Ecological Services (Xie et al. 2003), the value coefficient tables of land-use types in ecosystem service value, including gas regulation (GR), climate regulation (CR), water conservation (WC), soil formation and conservation (SFC), waste treatment (WT), biodiversity maintenance (BM), food production (FP), raw materials production (RMP), and entertainment culture (EC), were obtained.

The ecosystem service value equivalent factor 1 in Table 1 refers to the economic value of the annual natural grain output with 1 ha reaching China's average grain output, and the value demonstrates the potential of the relative contribution of ecological services produced by the ecosystem; the other ecosystem service value equivalent factors refer to the contributions of the ecological service values generated by the ecosystem to the food production service value of the farmland.

\subsubsection{Calculation of the Ecosystem Service Value of Economic Crop Production per Unit Area}

According to the definition of ecosystem service value equivalent factor by Xie et al. (2003) and the results of Tan and Wang (2012), the calculation formula used in this paper is as follows:

$$
V_{a}=\frac{1}{7} \sum_{i=1}^{n} \frac{S_{i} P_{i} A_{i}}{M} ;(i=1,2,3 \ldots n)
$$

where $V_{a}$ is the value of the service function of economic crop production per unit farm area (Dollars/ha); $S_{i}$ is the area of grain crop i (ha); $P_{i}$ is the average price of grain crop $\mathrm{i}$ (Dollars/t); $A_{i}$ is the output of grain crop i per unit farm area (t/ha); and $M$ is the total area of $n$ food crops (ha).

Table 2 shows the productive service value of economic crops per unit farm in Gansu Province from 2008 to 2017. Except for a slight decline in 2009, the productive service 
Table 2 The productive service value of economic crops in unit farm for Gansu Province in 2008 - 2017 (Dollars /ha)

\begin{tabular}{lllllllllll}
\hline Items & 2008 & 2009 & 2010 & 2011 & 2012 & 2013 & 2014 & 2015 & 2016 & 2017 \\
\hline Value & 142.06 & 141.01 & 152.25 & 169.29 & 197.08 & 201.34 & 206.55 & 214.26 & 220.10 & 225.44
\end{tabular}

value of economic crops per unit farm in Gansu Province increased each year, and there was a significant linear positive correlation between the two $\left(R^{2}=0.93885 ; p<0.05\right)$ (Fig. 2).

\subsubsection{Calculation of the Unit Price of the Agricultural Ecosystem Service Value}

The calculation formula of the unit price of the agricultural ecosystem service value in Gansu Province used in this paper was based on the research of Tan and Wang (2012):

$$
V_{i j}=e_{i j} V_{a}, ;(i=1,2,3 \ldots 9 ; j=1,2,3 \ldots 6)
$$

where $V_{i j}$ is the unit price of the $i$ ecological service value in land $j$ (Dollars/ha); and $E_{i j}$ is the $i$ ecosystem service value equivalent factor in land $j$.

\subsubsection{Calculation of the Agroecological Service Value}

The calculation formula of the agroecological service value of Gansu Province was based on the research of Tan and Wang (2012):

$$
V=\sum_{\mathrm{i}=1}^{9} \sum_{\mathrm{j}=1}^{6} S_{j} V_{i j} ; \cdots(i=1,2,3 \ldots 9 ; j=1,2,3 \ldots 6)
$$

where $V$ is the total value of agroecological service in Gansu Province (Dollars); $S_{j}$ is the area of land of category $j(\mathrm{ha})$; and $V_{i j}$ is the unit price of ecological service value $\mathrm{i}$ in land $j$ (Dollars/ha).

Fig. 2 Regression graph of production service value per unit of cash crop

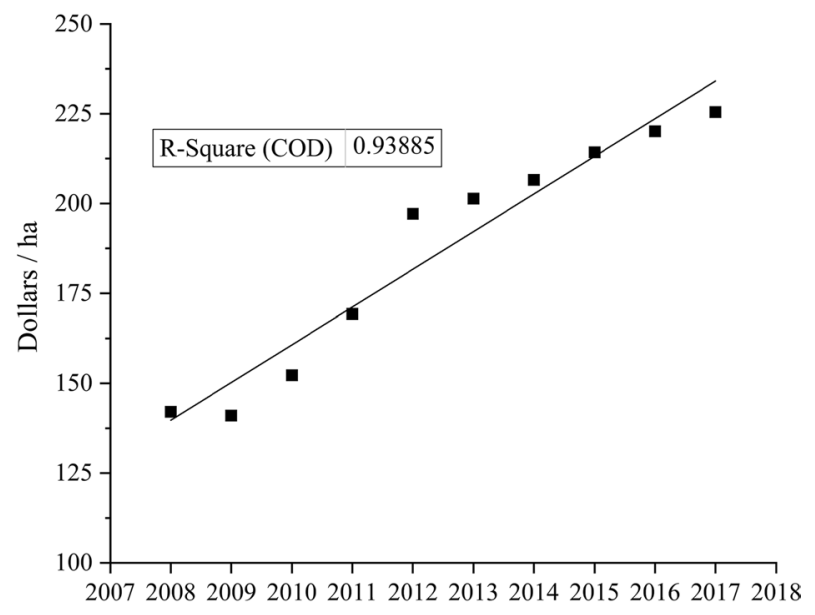


The experimental data were processed and analyzed in SPSS 24.0, and the charts were generated by ArcGIS 10.5 and Origin Pro 9.0.

\section{Results}

\subsection{Value Compositions of the Agroecological Service Function}

In the 10-year period 2008-2017, the total value of the agroecological service function in Gansu Province reached $3.285 \times 10^{12}$ Dollars. From 2008 to 2017, the total value of the agroecological service function in Gansu Province increased each year $\left(2.46 \times 10^{10}\right.$ Dollars, $2.46 \times 10^{10}$ Dollars, $2.67 \times 10^{10}$ Dollars, $2.94 \times 10^{10}$ Dollars, $3.39 \times 10^{10}$ Dollars, $3.47 \times 10^{10}$ Dollars, $3.53 \times 10^{10}$ Dollars, $3.66 \times 10^{10}$ Dollars, $3.98 \times 10^{10}$ Dollars and $4.28 \times 10^{10}$ Dollars, respectively (Fig. 3). In Fig. 3, it is clear that the agroecosystem service function value of Gansu Province from 2009 to 2012 exhibited a rapid increasing trend. After peaking at the maximum value (15\%) in 2012, the annual growth rate dramatically decreased until 2014. After 2014, the agroecosystem service function value of Gansu Province began to increase steadily.

\subsection{Changes in the Values of Different Agroecosystem Services}

Figure 4 shows that the values of different agroecosystem services in years 2008-2017 showed increasing trends, but their contributions to the total value of agroecological services of Gansu Province differed: SFC $(18.85 \%)>$ WC $(16.25 \%)>$ WT $(14.47 \%)>$ BM $(14.19 \%)>\operatorname{GR} \quad(13.08 \%)>$ CR $\quad(11.97 \%)>$ RMP $\quad(7.92 \%)>$ FP $\quad(4.80 \%)>$ EC $\quad(2.89 \%)$, which was similar to the results of Tan's research on the agroecosystem services value in Lanzhou city, Gansu Province, in 2008 (Tan and Wang 2012).

Fig. 3 The agroecosystem service function value and the rate of increase of Gansu Province in 2008-2017

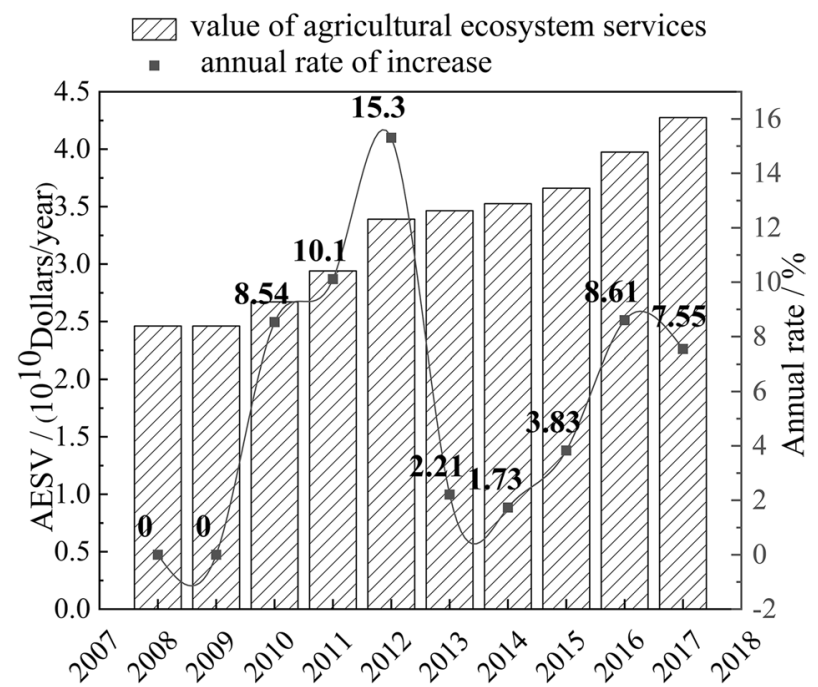


Fig. 4 The values of different agroecosystem service functions of Gansu Province in $2008-2017$

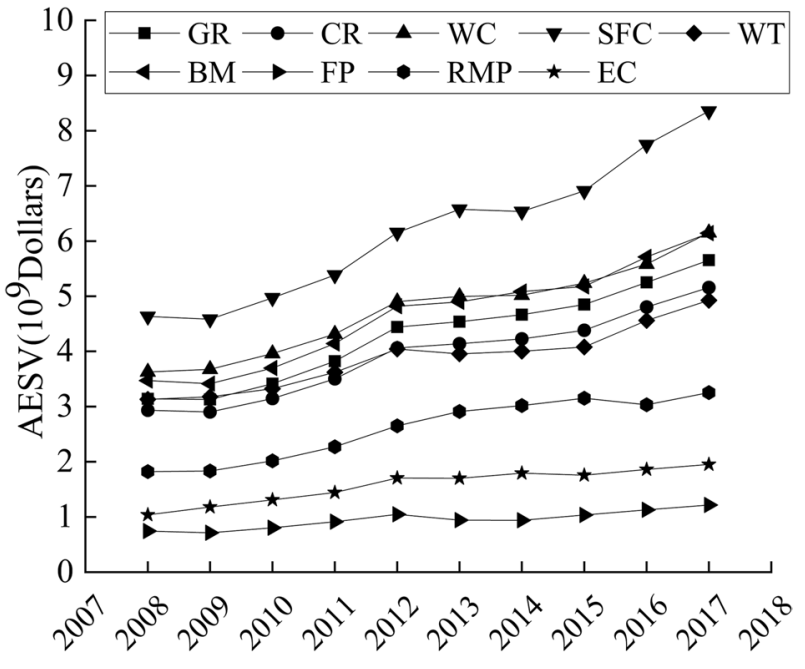

The proportion of the SFC value was the largest, which was related to the high SFC value of forest land, grassland and water bodies, and the extensive adoption of soil and water conservation measures. Similar to the annual growth rate of the total value of agroecological services, the SFC value of Gansu Province reached a peak in 2012 and declined sharply from 2012 to 2014, this is mainly due to the reduction of agricultural land area, some soil pollution and some abandonment of farmland and the decline in production which were caused by the acceleration of urbanization in recent years.

The figure for the WC value had the second largest proportion. After reaching a peak in 2011, its annual growth rate (Fig. 5) exhibited a declining trend each year from 2011 to 2014 , though it slowly increased after 2014. This result may be related to the high water conservation values of forest lands, water bodies and grasslands in Gansu Province. It may also be related to the accurate understanding of the current situation of water resources in Gansu Province in recent years, in which drought resistance and water saving measures were actively implemented and water resources were effectively utilized and protected (Akiyama et al. 2017).

The proportion of EC was the lowest, and its annual growth rate dramatically fluctuated and exhibited a general declining trend (Fig. 5). At the same time, Table 1 shows that the WT of farmland in had the highest unit price, followed by that of SFC and FP. The EC was the lowest. The EC of the agroecosystem was insufficient and needs further cultivation and development. At this stage, the value of large-scale sightseeing agriculture had increased greatly, such as the Rapeseed Flower Belt in Menyuan County, Qinghai Province, China. Therefore, we should vigorously develop leisure and tourism agriculture in Gansu Province (Cao et al. 2020; Lu et al. 2018) and consider the uniqueness of distinctive landscape features and cultural resources (Wang et al. 2013).

The WT value was followed by the SFC value and the WC value. In 2008-2017, the WT values in different agricultural lands showed moderate growth trends (Fig. 4). However, after 2010, the annual growth rate declined and then remained stable after 2013 (Fig. 5). This result may be due to the recycling and harmless utilization of waste from agroecosystems and other ecosystems. With the development of society, the economic 


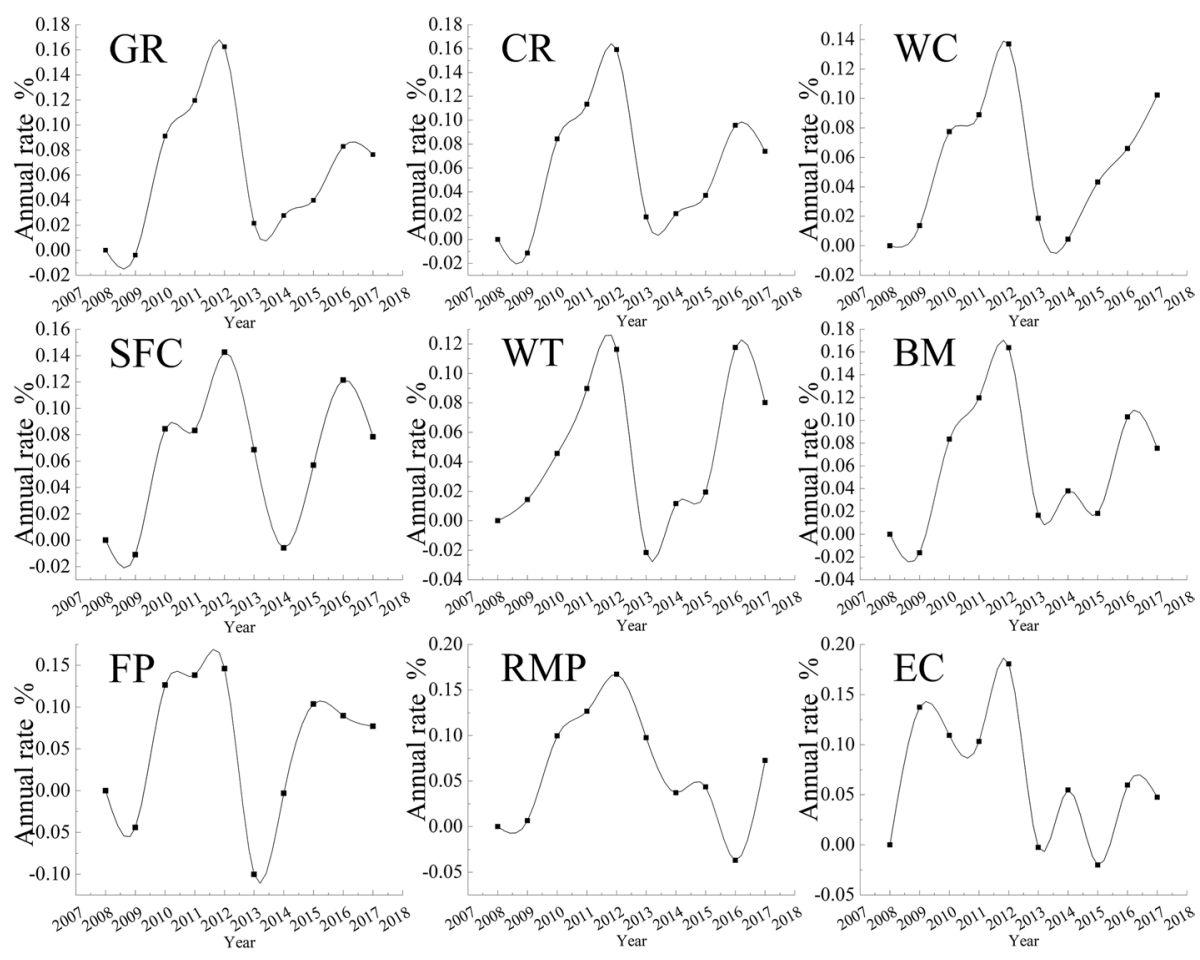

Fig. 5 The annual change in the agroecosystem service value in Gansu Province

structure has been continuously optimized and adjusted, and science and technology have been continuously developing. For this reason, the efficiency of agroecosystem waste treatment has been increasing. The proportion of WT to the agroecological service value also increased. The decline in the annual growth rate of the WT may be related to the sustainability of the WT of the corresponding agricultural lands.

From 2008 to 2017, the GR, CR, and BM of the agroecosystem accounted for the same proportions of the agroecological service value in Gansu Province, and the annual growth rates of GR, CR, and RMP were similar (Fig. 5). GR and CR had auxiliary and supporting effects on life support systems, and they can affect most biological and ecological processes on Earth spanning genetics, organismal physiology and life-history, population distributions and dynamics, community structure, and ecosystem functioning (Scheffers et al. 2016). To survive in an agroecosystem, organisms must adapt to changes in gas and climate.

Figure 4 shows that the contribution of BM to the annual average value of agroecological services in Gansu Province was $4.785 \times 10^{8}$ Dollars in the past ten years. Compared to the research done by Xie et al. (2008). on the Qinghai-Tibet Plateau, the contribution of $\mathrm{BM}$ to the value of agroecological services was $2.25 \times 10^{8}$ Dollars, which was $79.22 \%$ more than the result in this paper. This result indicated that the agroecosystem of Gansu Province had low biodiversity, the food chain was simple, and the contribution of organisms to the agroecosystem service value was relatively low, which encourages us to promote the development of agricultural biodiversity in Gansu Province. 


\section{Discussion}

The ecological environment is a complex, comprehensive and fuzzy system, and the current evaluation methods are not scientific and comprehensive; thus, the evaluation of ESV has uncertainties. Hou et al. (2013) described uncertainty as an analysis of state of limited knowledge. Uncertainty is related to the classification, selection and indicators of an ecosystem service type. In addition, people's preferences for ecological service functions are still uncertain. In other words, people's subjective judgments will cause a level of uncertainty (Spangenberg and Settele 2010). Due to the availability of data and technical limitations, the assignment of some socioeconomic data and entertainment culture may be inaccurate to a certain degree. In addition, some models use certain restrictions, assumptions, simplifications, formulas and parameters to quantify these key indicators, which are the reasons for model uncertainty (Katz 2001).

It is necessary to analyze the ecological security of ecologically fragile areas in arid inland river basins to protect these important ecosystems. The degradation or loss of ecosystems affects not only human safety and health but also regional and global ecological security. To study ecological security, many researchers have proposed methods for calculating the ESV of ecological security (Liu et al. 2018; Yang et al. 2019). Uncertainty prevails in the evaluation process. Ecosystem services need to be comprehensively considered in multiple disciplines, and current assessment methods are still insufficient (Hou et al. 2013). However, with our gradual understanding of the ecosystem and progress in the synthesis and methods of evaluation disciplines, the uncertainty will gradually decrease.

Although there are still some existing defects, the discussion of ecological security issues from the perspective of the equivalent factor method can be used to understand the overall ecological status of the arid area in Northwest China from a macro perspective. This method also ignores differences within ecosystems of the same land-use type. In addition, this method does not specifically consider the differences and subordinate characteristics of different research areas. Different land-use intensities will also affect the value of ecosystem services (Gaglio et al. 2020). Therefore, in view of these shortcomings, in future research, it is still necessary to further explore a reasonable, scientific, and comprehensive evaluation index system for ecological environment quality. To address ecological problems in the arid inland river basins of Northwest China, a series of ecological conservation and restoration projects was initiated in 2000, including the Ecological Water Conveyance Project (EWCP), artificial forest planting, and the establishment of nature reserves. After assessing the ecological protection and restoration of the Heihe River and the Tarim River, Zhu et al. (2016) proposed that water resources are limited in the entire reaches of arid inland river basins, and ecological protection is more important than ecological restoration.

Based on the research results, this research proposes suggestions for ecological protection in this area. Gansu Province is an important area in the Hexi Corridor and an important part of the "One Belt and One Road" initiative. The ecological construction of Gansu Province should adhere to the principle of "adjusting the measures to the local conditions". Reasonable restoration measures should be formulated according to the land-use types, climate conditions, topography, water balance problems and other factors of the different regions. In the northern and southern regions with sparse vegetation, attention should be paid to improving the construction of shelter forests and the rational development and utilization of wasteland without damaging the environment. Oasis areas, cultivated land and basic farmland that occupy an important position in the local area should be strictly protected. A barrier in the northern region is needed to prevent the desert from moving to the 
southern region. At the same time, it should be noted that although large-scale afforestation can provide protection for ecological security, it also needs to be reasonably assessed to avoid derivative ecological problems caused by construction, such as fast-diffusion damage by insects. The construction of the ecological environment should be linked with relevant ecological resources to enhance the overall stability of the region. Large-scale capital investment is very important to ecological construction. Earlier capital investment will gain benefits after a long period of time, and the dividends of ecological construction will appear. It must rely on local continuous eco-environmental recycling construction rather than blindly and continuously investing a large amount of money, and strong sustainability in ecological protection is the most rational effect.

In the static value composition of the different agroecological services, the agricultural ecosystem is dominated by farmland ecosystems, which are sources of food production and raw material production. The increase in value may be affected by many factors. For example, when calculating the equivalent factor, the selected crop products in Gansu Province are potato, corn and wheat. The prices of the three crops have risen in ten years, and there may be inflation factors. Correspondingly, the value of ecosystem services has increased in the calculation. Another study showed that the loss of value of ecosystem services is mainly due to the reduction of arable land, which is consistent with the results of this study (Chen et al. 2020). The value of SFC was highest, this result is similar to that of Tan and Wang (2012). Diversified agricultural ecosystems may enhance specific ecosystem services, and changes in agricultural ecosystems may affect the strategy of sustainable development (Duguma et al. 2019).

In today's world, maintaining land and ecological security has become a top priority for governments of all countries. Semiarid regions account for approximately $40 \%$ of the world's land area. The ecosystems in arid and semiarid regions are very sensitive to climate change and human activities. Ecosystem service value assessments can fundamentally help to solve ecological problems to maintain ecological and economic sustainability, especially in arid and semiarid areas with significant ecological problems. This article provides a reference for the evaluation of ecosystem service value on national and regional scales and has guiding significance for urban development and ecological environment layout planning in arid regions.

\section{Conclusions}

Through the study of the structure, time changes and different functional types of the agricultural ecological service value in Gansu Province, it was found that the social ecological balance and the agricultural ecological balance are very important for the sustainability of the development of arid and semiarid regions.

From 2008 to 2017, the value of agricultural ecosystem services in Gansu Province grew steadily. The ESV of soil formation and protection was the highest and increased the fastest. The value growth rate of entertainment and cultural services was the highest. This result may be related to the land policy of the local government. According to the proportion of each ecological function and the reason analysis, the ecological environment in this area is more complicated. The construction of the ecological environment should be linked with the relevant ecological resources to enhance the overall stability of the region, which is conducive to the rational use of the functions of the various ecosystems in these areas. The evaluation result of the service value of agricultural ecosystems is conducive to the sustainability of the development of arid and semiarid regions. 
These results help emphasize the importance of protecting ecosystems and their services at the regional level. The research methods in this article are also applicable to the formulation and implementation of decisions in areas related to ecosystem services and management, such as nature and biodiversity protection, spatial planning, agriculture, forestry, water management, and the development of rural tourism. In addition, the driving force analysis shows that the significant drivers of land use and ecosystem service changes since 1750 are socioeconomic, political and technical drivers. These factors are critical to the value of agricultural ecosystem services (Baude et al. 2019). The results of this research may help us better understand the value of agroecosystems and their benefits to environmental quality and social well-being, especially in arid regions. Therefore, in the vigorous development process of the agricultural economy, attention should be paid to the role of agroecological balance and the importance of agroecological service functions to promote the construction of ecological agriculture. It will be very important to transfer the structure, improve the efficiency of production, vigorously promote the construction of ecological civilization, continuously maintain the balance of agroecosystems, and continuously improve the value of agroecosystem services.

Authors' Contributions All authors contributed to the study conception and design. Conceptualization: Zhang Songlin; Methodology: Liu Yang; Formal analysis and investigation: Jia Yi and Liu Yang; Writingoriginal draft preparation: Jia Yi and Liu Yang; Writing—review and editing: Zhang Songlin.

Funding This article was funded by the National Natural Science Foundation of China, Grant numbers 51068025 and 41561046 .

Data Availability All data generated or analyzed during this study are included in this published article.

Code Availability The data used to support the findings of this study are available from the corresponding author upon request.

\section{Declarations}

Conflicts of Interest The authors declare that they have no conflicts of interest.

\section{References}

Abd-Elaty I, Pugliese L, Mesaros P, Mesaros P, Shinawi A (2020) Simulation-based solutions reducing soil and groundwater contamination from fertilizers in arid and semi-arid regions: case study the Eastern Nile Delta. Egypt Int J Environ Res Public Health 17(24):9373. https://doi.org/10.3390/ IJERPH17249373

Akiyama T, Kharrazi A, Li J, Avtar R (2017) Agricultural water policy reforms in China: a representative look at Zhangye City, Gansu Province. China Environ Monit Assess 190(1):9. https://doi.org/ $10.1007 / \mathrm{s} 10661-017-6370-\mathrm{Z}$

Azaiez N, Alleoua A, Baazaoui N, Qhtani N (2020) Assessment of soil loss in the Mirabah Basin: An overview of the potential of agricultural terraces as ancestral practices (Saudi Arabia). Open J Soil Sci 10:159-180. https://doi.org/10.4236/ojss.2020.105008

Baude M, Meyer BC, Schindewolf M (2019) Land use change in an agricultural landscape causing degradation of soil-based ecosystem services. Sci Total Environ 659:1526-1536. https://doi.org/10. 1016/j.scitotenv.2018.12.455

Cao S, Suo X, Xia C, Yu Z, Feng F (2020) Net value of forest ecosystem services in China. EcolEng 142:105645. https://doi.org/10.1016/j.ecoleng.2019.105645 
Chen J, Yu L, Yan F, Zhang S (2020) Ecosystem service loss in response to agricultural expansion in the small Sanjiang Plain, Northeast China: process, driver and management. Sustainability 12:2430. https://doi.org/10.3390/su12062430

Cortinovis C, Geneletti D (2018) Mapping and assessing ecosystem services to support urban planning: a case study on brownfield regeneration in Trento. Italy One Ecosyst 3:e25477. https://doi.org/10. 3897/oneeco.3.e25477

Costanza R, d'Arge R, de Groot R, Farber S, Grasso M, Hannon B, Limburg K, Naeem S, O'Neill RV, Paruelo J, Raskin RG, Sutton P, Belt M (1997) The value of the world's ecosystem services and natural capital. Nature 387:253-260. https://doi.org/10.1038/387253a0

Dietz L, Horve P, Coil D, Fretz M, Eisen J, Van Den Wymelenberg K (2020) 2019 Novel Coronavirus (COVID-19) pandemic: built environment considerations to reduce transmission. MSystems 5(2):e0245-e320. https://doi.org/10.1128/mSystems.00245-20

Del Rio T, Willemen L, Vrieling A, Nelson A (2020) Understanding intra-annual dynamics of ecosystem services using satellite image time series. Remote Sens 12(4):1-19. https://doi.org/10.3390/rs 120 40710

Duguma M, Feyssa D, Biber-Freudenberger L (2019) Agricultural biodiversity and ecosystem services of major farming systems: a case study in Yayo Coffee Forest Biosphere Reserve. Southwestern Ethiopia Agriculture 9(3):48. https://doi.org/10.3390/agriculture9030048

Farber S, Costanza R, Wilson M (2002) Economic and ecological concepts for valuing ecosystem services. Ecol Econ 41:375-392. https://doi.org/10.1016/S0921-8009(02)00088-5

Food and Agricultural Organization (FAO) (2018) FAO stat Database. Rome, Italy. Retrieved from: http://www.fao.org/faostat/en/. Accessed 10/2/2021

Gaglio M, Aschonitis V, Castaldelli G, Fano EA (2020) Land use intensification rather than land cover change affects regulating services in the mountainous Adige river basin (Italy). EcosystServ 45:101158. https://doi.org/10.1016/j.ecoser.2020.101158

Hou Y, Burkhard B, Müller F (2013) Uncertainties in landscape analysis and ecosystem service assessment. J Environ Manag 127:S117-S131. https://doi.org/10.1016/j.jenvman.2012.12.002

Kadaverugu A, Rao N, Viswanadh K (2021) Quantification of flood mitigation services by urban green spaces using InVEST model: a case study of Hyderabad city, India. Model Earth Syst Environ 7:589-602. https://doi.org/10.1007/s40808-020-00937-0

Katz R (2001) Techniques for estimating uncertainty in climate change scenarios and impact studies. Clim Res 20(2):167-185. https://doi.org/10.3354/cr020167

KhosraviMashizi A, Heshmati GA, Salman Mahini AR, Escobedo FJ (2019) Exploring management objectives and ecosystem service trade-offs in a semi-arid rangeland basin in southeast Iran. Ecol Indic 98:794-803. https://doi.org/10.1016/j.ecolind.2018.11.065

Li Z, Pan J (2018) Spatiotemporal changes in vegetation net primary productivity in the arid region of Northwest China, 2001 to 2012. Front Earth Sci 12:108-124. https://doi.org/10.1007/ s11707-017-0621-8

Liu X, Ziv G, Bakshi BR (2018) Ecosystem services in life cycle assessment - Part 1: a computational framework. J Clean Prod 197:314-322. https://doi.org/10.1016/j.jclepro.2018.06.164

Longato D, Gaglio M, Boschetti M, Gissi E (2019) Bioenergy and ecosystem services trade-offs and synergies in marginal agricultural lands: a remote-sensing-based assessment method. J Clean Prod 237:117672. https://doi.org/10.1016/j.jclepro.2019.117672

Lu C, Li W, Pang M, Xue B, Miao H (2018) Quantifying the economy-environment interactions in tourism: case of Gansu Province. China Sustainability 10(3):711. https://doi.org/10.3390/su10030711

Lu Z, Wei Y, Xiao H, Zou S, Ren J, Lyle C (2015) Trade-offs between midstream agricultural production and downstream ecological sustainability in the Heihe River basin in the past half century. Agric Water Manag 152:233-242. https://doi.org/10.1016/j.agwat.2015.01.022

Millenium Ecosystem Assessment (2005) Ecosystems and human well-being: biodiversity synthesis. World Resources Institute, Washington DC, p 77e101

Odum HT (1996) Environmental accounting: emergy and environmental decision making. John Wiley and Sons, New York

Peng J, Zhao S, Dong J, Liu Y, Meersmans J, Li H, Wu J (2019) Applying ant colony algorithm to identify ecological security patterns in megacities. Environ Model Softw 117:214-222. https://doi.org/ 10.1016/j.envsoft.2019.03.017

Posner S, Mckenzie E, Ricketts T (2016) Policy impacts of ecosystem services knowledge. Proc Natl Acad USA 113(7):1760-1765. https://doi.org/10.1073/pnas.1502452113

Santos-Martín F, Zorrilla-Miras P, García-Llorente M, Quintas-Soriano C, Montes C, Benayas J, Gomez S, Paracchini ML (2019) Identifying win-win situations in agricultural landscapes: an integrated 
ecosystem services assessment for Spain. LandscEcol 34(7):1789-1805. https://doi.org/10.1007/ s10980-019-00852-5

Scheffers B, De Meester L, Bridge L, Hoffmann A, Pandolfi J, Corlett R, Butchart S, Pearce-Kelly P, Kovacs K, Dudgeon D, Pacifici M, Rondinini C, Foden W, Martin T, Mora G, Bickford D, Watson J (2016) The broad footprint of climate change from genes to biomes to people. Science 354(6313):aaf7671. https://doi.org/10.1126/science.aaf7671

Sharafatmandrad M, Mashizi A (2021) Temporal and spatial assessment of supply and demand of the wateryield ecosystem service for water scarcity management in arid to semi-arid ecosystems. Water ResourManag 35:63-82. https://doi.org/10.1007/s11269-020-02706-1

Spangenberg J, Settele J (2010) Precisely incorrect? Monetising the value of ecosystem services. Ecol Complex 7(3):327-337. https://doi.org/10.1016/j.ecocom.2010.04.007

Sun Q, Qi W, Yu X (2021) Impacts of land use change on ecosystem services in the intensive agricultural area of North China based on Multi-scenario analysis. ALEX ENG J 60(1):1703-1716. https://doi.org/ 10.1016/J.AEJ.2020.11.020

Swinton S, Lupi F, Robertson G, Hamilton S (2007) Ecosystem services and agriculture: cultivating agricultural ecosystems for diverse benefits. Ecol Econ 64(2):245-252. https://doi.org/10.1016/j.ecolecon. 2007.09.020

Tan C, Wang S (2012) An empirical analysis of the value of agricultural ecosystem services in Lanzhou. Journal of Southwest Agricultural University (Social Sciences Edition) (in Chinese with English abstract).10(04):62-66, CNKI:SUN:SCSM.0.2012-04-015

Torabi Haghighi A, Abou Zaki N, Rossi PM, Noori R, Hekmatzadeh AA, Saremi H, Kløve B (2020) Unsustainability syndrome-from meteorological to agricultural drought in arid and semi-arid regions. Water 12(3):838. https://doi.org/10.3390/w12030838

Wang L, Cheng S, Zhong L, Mu S, Dhruba B, Ren G (2013) Rural tourism development in China: principles, models and the future. J MolSci 10(1):116-129. https://doi.org/10.1007/s11629-013-2501-3

Wang Q, Su M (2020) A preliminary assessment of the impact of COVID-19 on environment - a case study of China. Sci Total Environ 728:138915. https://doi.org/10.1016/j.scitotenv.2020.138915

Wu J (2013) Landscape sustainability science: ecosystem services and human well-being in changing landscapes. LandscEcol 28:999-1023. https://doi.org/10.1007/s10980-013-9894-9

Xie G, LU C, Leng Y (2003), Ecological assets valuation of the Tibetan Plateau Journal of Natural Resources, J Nat Resour 18(2):189-196 (in Chinese with English abstract) https://doi.org/10.11849/ zrzyxb.2003.02.010

Xie G, Zhen L, Lu CX, Xiao Y, Cheng C (2008) Expert knowledge-based valuation method of ecosystem services in China. J Nat Resour. 23 (5): 911-919 (in Chinese with English abstract). https://doi.org/10. 11849/zrzyxb.2008.05.019

Yang Y, Wang K, Liu D, Zhao X, Fan J (2020) Effects of land-use conversions on the ecosystem services in the agro-pastoral ecotone of Northern China. J Clean Prod 249:119360. https://doi.org/10.1016/j.jclep ro.2019.119360

Yang Y, Zheng H, Kong L, Huang B, Xu W, Ouyang Z (2019) Mapping ecosystem services bundles to detect high- and low-value ecosystem services areas for land use management. J Clean Prod 225:1117. https://doi.org/10.1016/j.jclepro.2019.03.242

Zhang W, Ricketts T, Kremen C, Carney K, Swinton S (2007) Ecosystem services and dis-services to agriculture. Ecol Econ 64(2):253-260. https://doi.org/10.1016/j.ecolecon.2007.02.024

Zhang Y, Singh S, Bakshi B (2010) Accounting for ecosystem services in life cycle assessment, part i: a critical review. Environ SciTechnol 44(7):2232-2242. https://doi.org/10.1021/es9021156

Zhao Y, Zou X, Cheng H, Jia H, Wu Y, Wang G, Zhang C, Gao S (2006) Assessing the ecological security of the Tibetan plateau: Methodology and a case study for Lhaze County. J Environ Manage 80(2):120131. https://doi.org/10.1016/j.jenvman.2005.08.019

Zhong L, Wang J, Zhang X, Ying L (2020) Effects of agricultural land consolidation on ecosystem services: trade-offs and synergies. J Clean Prod 264:121412. https://doi.org/10.1016/j.jclepro.2020.121412

Zhou S, Huang Y, Wang G, Yu B (2015) Effects of human activities on the eco-environment in the middle Heihe River Basin based on an extended environmental Kuznets curve model. EcolEng 76:14-26. https://doi.org/10.1016/j.ecoleng.2014.04.020

Zhu Y, Chen Y, Ren L, Lü H, Xu M (2016) Ecosystem restoration and conservation in the arid inland river basins of Northwest China: problems and strategies. EcolEng 94:629-637. https://doi.org/10.1016/j. ecoleng.2016.06.107

Publisher's Note Springer Nature remains neutral with regard to jurisdictional claims in published maps and institutional affiliations. 


\section{Authors and Affiliations}

\section{Yi Jia ${ }^{1}$ - Yang $\mathrm{Liu}^{2,3} \cdot$ Songlin Zhang ${ }^{1}$}

Yi Jia

1543287050@qq.com

Yang Liu

lymm1125@163.com

1 School of Geography and Environmental Science, Northwest Normal University, Lanzhou 730070, People's Republic of China

2 State Key Laboratory of Cryospheric Sciences, Northwest Institute of Eco-Environment and Resources, Chinese Academy of Sciences, Lanzhou 730000, People's Republic of China

3 University of Chinese Academy of Sciences, No.19A Yuquan Road, Beijing 100049, People's Republic of China 